\title{
Classification of Induced Magnetic Field Signals for the Microstructural Characterization of Sigma Phase in Duplex Stainless Steels
}

\author{
Edgard M. Silva ${ }^{1}$, Leandro B. Marinho ${ }^{2}$, Pedro P. Rebouças Filho ${ }^{2}$, João P. Leite ${ }^{1}$, \\ Josinaldo P. Leite ${ }^{1}$, Walter M. L. Fialho ${ }^{1}$, Victor Hugo C. de Albuquerque ${ }^{3}$ and \\ João Manuel R. S. Tavares ${ }^{4, *}$ \\ 1 Instituto Federal de Educação, Ciência e Tecnologia da Paraíba, Rua José Américo de Almeida, \\ 707-Nordeste I, Guarabira, João Pessoa-PB 58200-000, Brazil; edgardmsilva@ifpb.edu.br (E.M.S.); \\ joao.leite100@yahoo.com.br (J.P.L.); josinaldo@ct.ufpb.br (J.P.L.); wmlfialho@yahoo.com.br (W.M.L.F.) \\ 2 Programa de Pós-Graduação em Ciências da Computação, Instituto Federal de Educação, Ciência e \\ Tecnologia do Ceará, Av. Parque Central-Distrito Industrial I, Maracanaú-CE 61939-140, Brazil; \\ leandro.marinho@ppgcc.ifce.edu.br (L.B.M.); pedrosarf@ifce.edu.br (P.P.R.F.) \\ 3 Programa de Pós-Graduação em Informática Aplicada, Universidade de Fortaleza, Av. Washington Soares, \\ 1321, Edson Queiroz, Fortaleza-CE 60811-905, Brazil; victor.albuquerque@unifor.br \\ 4 Instituto de Ciência e Inovação em Engenharia Mecânica e Engenharia Industrial, Departamento de \\ Engenharia Mecânica, Faculdade de Engenharia, Universidade do Porto, Porto 4200-465, Portugal \\ * Correspondence: tavares@fe.up.pt; Tel.: +351-22-508-1487
}

Academic Editor: Hugo F. Lopez

Received: 7 May 2016; Accepted: 7 July 2016; Published: 14 July 2016

\begin{abstract}
Duplex stainless steels present excellent mechanical and corrosion resistance properties. However, when heat treated at temperatures above $600{ }^{\circ} \mathrm{C}$, the undesirable tertiary sigma phase is formed. This phase presents high hardness, around $900 \mathrm{HV}$, and it is rich in chromium, the material toughness being compromised when the amount of this phase is not less than $4 \%$. This work aimed to develop a solution for the detection of this phase in duplex stainless steels through the computational classification of induced magnetic field signals. The proposed solution is based on an Optimum Path Forest classifier, which was revealed to be more robust and effective than Bayes, Artificial Neural Network and Support Vector Machine based classifiers. The induced magnetic field was produced by the interaction between an applied external field and the microstructure. Samples of the 2205 duplex stainless steel were thermal aged in order to obtain different amounts of sigma phases (up to $18 \%$ in content). The obtained classification results were compared against the ones obtained by Charpy impact energy test, amount of sigma phase, and analysis of the fracture surface by scanning electron microscopy and X-ray diffraction. The proposed solution achieved a classification accuracy superior to $95 \%$ and was revealed to be robust to signal noise, being therefore a valid testing tool to be used in this domain.
\end{abstract}

Keywords: microstructural characterization; signal classification; Optimum Path Forest; Bayes; Artificial Neural Network; Support Vector Machine

\section{Introduction}

Duplex stainless steels (DSS) present excellent mechanical and corrosion resistance properties when the steel microstructures are only composed by austenite $(\gamma)$ and ferrite $(\alpha)$ in approximately equal amounts $[1,2]$. These materials have been widely used in marine and petrochemical industries, desalination services and paper mills, just to cite a few examples [3-5]. However, undesirable tertiary phases such as sigma $(\sigma)$ and Chi $(\chi)$ may precipitate in these steels during hot forming 
or welding operations [6-8]. Sigma phase appears after holding times under temperatures between 600 and $950{ }^{\circ} \mathrm{C}$ and after cooling from high temperatures, which typically occurs, for example, in the heat-affected zone during welding operations. Good toughness properties can be achieved by applying proper annealing temperatures and cooling rates, which generally leads to satisfactory toughness properties in DSS $[9,10]$.

Sigma phase presents high hardness, with values around $900 \mathrm{HV}$, and is rich in chromium [11-14]. Therefore, an amount of $4 \%$ of this phase compromises the material toughness $[4,7,15]$. However, a low content of the sigma phase promotes considerable decreasing of toughness without notable influence on the hardness. For instance, the precipitation of $1.3 \%$ of sigma phase decreases the impact toughness around $7 \%$ from the solute treated condition relative to the aged one at $800^{\circ} \mathrm{C}$ for $10 \mathrm{~min}[4,7,16]$.

Austenite and ferrite phases form duplex stainless steels, but when heat treated, only ferrite phase suffers decomposition. Ferrite phase is ferromagnetic, while austenite and sigma phases are paramagnetic. Two phases are responsible for the embrittlement of a duplex stainless steel, sigma phase and alpha-line phase, known as $\sigma^{\prime}$, which is a ferrite phase rich in chromium. Sigma phase is formed above $550{ }^{\circ} \mathrm{C}$, and alpha-line phase below this temperature. Therefore, the ferrite decomposition leads to changes in the magnetic properties of the material and so magnetic-based inspection methods seem to be adequate for testing these steels [7,17-21]. Moreover, it is also known that the magnetic properties like coercivity and remanence are affected by microstructural modifications, and that the remanence measurement of the magnetic hysteresis loop is able to follow the formation of sigma phase even when presented in a low volume fraction $[17,18]$.

The presence of paramagnetic phases in heat treated duplex stainless steels changes the material magnetic permeability and therefore also the magnetic susceptibility. Hence, magnetic susceptibility based tests have been applied to DSS samples with different amounts of these phases, and decreased susceptibility has been found when the thermal aging times are high due to the formation of sigma phase. These tests have been used not only to detect sigma phase, but also to identify alpha-line phase being the same trend observed $[19,20]$. Additionally, the magnetic permeability assessed based on the interaction between a direct current (DC) magnetic field and the microstructure was used in [22] to follow the ferrite decomposition into alpha-line phase in a duplex stainless steel. The authors showed that, although alpha-line phase had nanostructure, the presence of this phase could be successfully detected.

Electromagnetic techniques [23], such as the Eddy Current Technique (ECT) and the Saturated Low-Frequency Eddy Current (SLOFEC) technique, have been used to characterize DSS samples. The SLOFEC technique uses an external DC magnetic field that reaches the magnetic saturation of the material sample under study. Both techniques have been able to evaluate sigma phase presence and estimate ferrite content. The advantages of using ECT in materials characterization have been studied by several authors [24-26]. However, neither the potentiality of this technique to characterize low amounts of sigma phase in duplex stainless steels or the correlation of the electromagnetic results with the ferrite content have been addressed. In addition, few material samples have been tested, which leaves some uncertainty about the reliability of the findings.

Another traditional method that has been adopted to characterize microstructures is an ultrasound [27-31], which has been particularly used to detect sigma phase [21-27]. Normando et al., in [6,7], analyzed the capability of the sound velocity to follow-up $\sigma$-phase formation at temperatures of 800 and $900{ }^{\circ} \mathrm{C}$ for times up to $2 \mathrm{~h}$. The sound velocity is influenced by the density and the elastic moduli of the material [32], and so the variations observed in the sound velocity indicated changes in terms of the material properties due to sigma phase formed from ferrite phase. Their measurements were revealed to be more accurate for aging times above $30 \mathrm{~min}[6,7]$. Silva et al. [28,29] also applied an ultrasound in microstructure characterization. They studied ferrite decomposition at temperatures of 425 and $475{ }^{\circ} \mathrm{C}$ and found that the changes of the sound speed are directly proportional to the variation of the material's hardness, which indicates sensitivity to transformation phases. Thus, 
the sound speed is an important nondestructive parameter for following-up the hardening kinetics of DSS.

The use of techniques of digital signal processing and machine learning has been quite common in engineering to tackle numerous and diverse applications [33-37]. In line with such applications, this work aimed to develop a solution for the automated detection of sigma phase in duplex stainless steels based on the processing and classification of signals from induced magnetic fields. With this goal, Optimum Path Forest (OPF), Bayes, Artificial Neural Network and Support Vector Machine based classifiers were studied and compared.

The proposed solution uses induced magnetic field signals, which are produced by DC by the interaction between an applied external field and the microstructure, and are classified by OPF classifier. The experiments conducted, which are described in the next section, confirmed that the developed solution is promising for following the decomposition of small ferrite particles at temperatures below $550{ }^{\circ} \mathrm{C}$ in the SAF 2205 (aka UNS S31803) duplex stainless steel (Sandvik, Sandviken, Sweden) as in [22], and also to successfully tracking sigma phase in the same steel.

\section{Experimental Procedures}

Samples of a SAF 2205 duplex stainless steel were thermally aged in an electric resistance furnace at $800{ }^{\circ} \mathrm{C}$ for times of $0.25,1$, and $2 \mathrm{~h}$, and at $900{ }^{\circ} \mathrm{C}$ for $2 \mathrm{~h}$, in order to obtain different amounts of sigma phase that were quantified through optical microscopy (FX 35XD NIKON Optic Microscopy, Nikon, Tokyo, Japan). The samples were prepared by mechanical polishing and electrolytic etch in a $10 \% \mathrm{KOH}$ solution, being the voltage and time applied equal to $3 \mathrm{~V}$ and $15 \mathrm{~s}$, respectively. The electrolytic etching with $10 \% \mathrm{KOH}$ solution reveals mainly sigma phase. The amount (\% volumetric fraction) of sigma phase presented in each sample was determined using a computational tool, which is based on techniques of image processing and analysis and on an artificial neural network, that has been used to characterize microstructures in previous studies [38-43]. Forty images were acquired from each material sample and the volume fraction was determined adopting a confidence interval of $95 \%$. Five samples were subjected to each treatment under study, and a sample in the as-received state was also analyzed; all samples had dimensions equal to $5 \mathrm{~mm} \times 10 \mathrm{~mm} \times 55 \mathrm{~mm}$. A Charpy impact test was performed on the samples subjected to the same thermal treatment, and the microstructures of the fracture surfaces were analyzed through scanning electron microscopy (SUPERSCAN SSX-550 SEM, Shimadzu Corporation, Kyoto, Japan).

To study the formation of sigma phase, an X-ray diffraction (XRD) test was performed using an X-ray Diffractometer from Shimadzu Corporation (Kyoto, Japan), model XRD-6000 vertical type, with $\mathrm{Cu}$ k- $\alpha$ radiation. The scanning angle adopted varied from $41^{\circ}$ to $53^{\circ}$ with steps of $0.02^{\circ}$.

\subsection{Induced Magnetic Fields}

For the application of the induced magnetic fields and acquisition of their values, the experimental setup shown in Figure 1 was used. In this setup, a solenoid is responsible for generating the external magnetic fields. The generated magnetic flux density is determined by a Hall Effect sensor (SS495A model, Honeywell S\&C, Morris Plains, NJ, USA). An external magnetic field of $211.5 \mathrm{~A} / \mathrm{m}$ was applied in the experiments.

No permanent magnetization was observed in the material. In order to assure statistical significance, fifty measurements of five hundred signals each were acquired from each material sample under study, resulting in a total of 25,000 points for analysis. The samples had a size of $5 \mathrm{~mm} \times 10 \mathrm{~mm} \times 15 \mathrm{~mm}$, and the measurements were performed on the $10 \times 15$ surface and $1 \mathrm{~mm}$ far from the edge, in order to avoid edge effects due to air interference. 


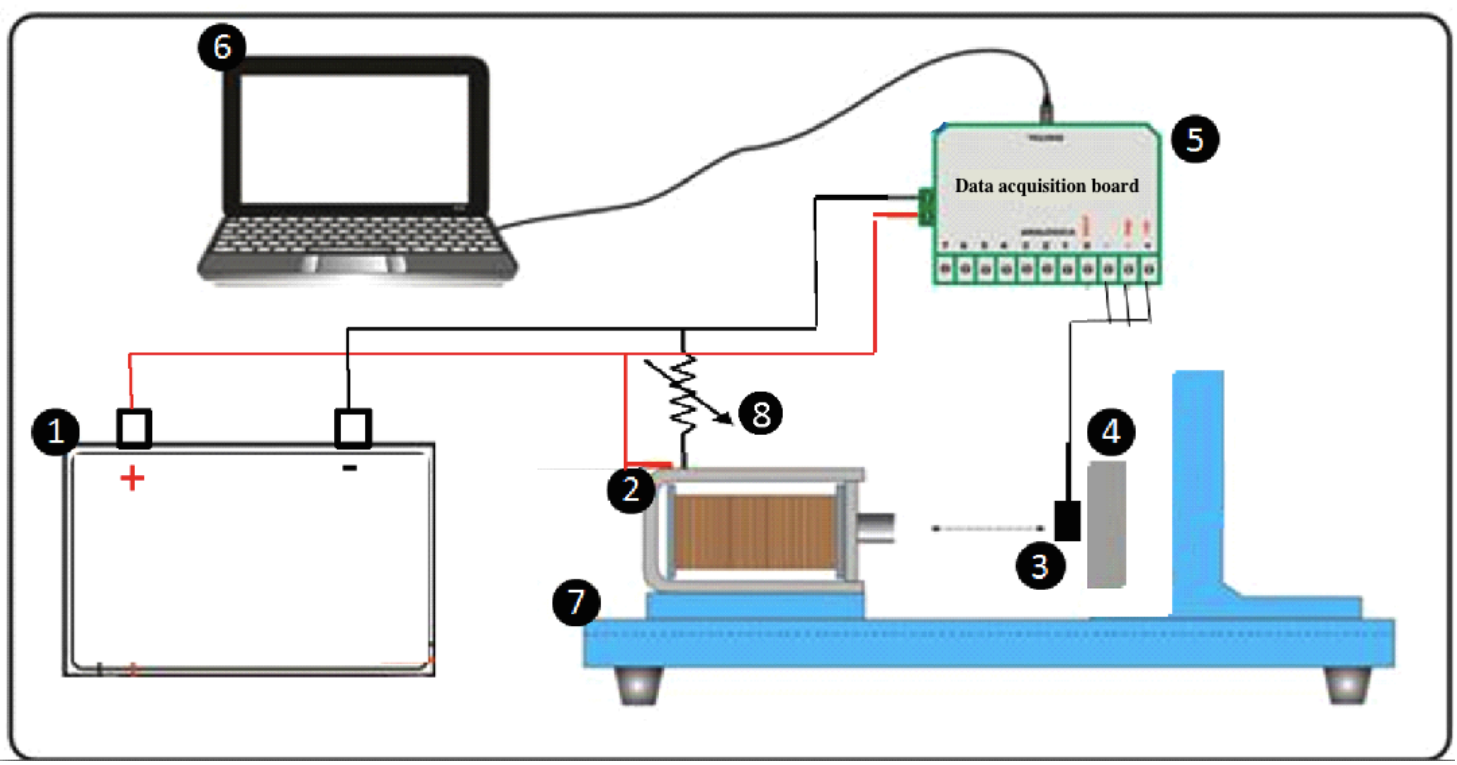

Figure 1. Experimental setup: (1) power supply; (2) solenoid; (3) Hall sensor; (4) sample; (5) data acquisition board; (6) computer; (7) bench test and (8) potentiometer.

\subsection{Machine Learning}

In this work, we carried out a systematic study to address the problem of microstructural characterization based on the classification of induced magnetic field signals. Several computer classifiers have been used to tackle similar problems, but a recent and powerful one has gained particular attention: OPF [44-46]. This classifier has shown some advantages over more traditional ones: (i) it is free of hard-to-calibrate control parameters; (ii) it does not assume any shape/separability of the feature space; (iii) it has much faster training phases; (iv) it can reach decisions based on global criteria, and, finally; (v) it provides excellent performance on small datasets. Moreover, OPF does not interpret the classification task as a hyperplane optimization problem, but as the computation of optimum paths from some key patterns (known as aka prototypes) to the remaining nodes. By this means, each prototype becomes a root from its optimum path tree, and then each node is identified according to its strongly connected prototype. This step defines a discrete optimal partition (known as influence region) of the feature space. Thus, due to its high efficiency and accuracy, together with its parameter independence and robustness to highly non-linear datasets, OPF seemed to be a very suitable solution to perform the automated classification of induced magnetic field signals in microstructural characterization.

More detailed descriptions about the supervised OPF algorithm and some of its recent applications can be found, for example, in [36]—classification of ultrasonic signals, [47]—land cover classification, [48,49] - electroencephalogram (EEG) and electrocardiogram (ECG) signal identification and recognition, [50] — characterization of graphite particles in metallographic images, [51,52]—-learning-time constrained applications, [53]—segmentation and classification of human intestinal parasites, and in [54]—intrusion detection in computer networks.

To confirm and compare the suitability of OPF for this classification problem, Support Vector Machine configured with radial basis function kernel (SVM-RBF) [55,56], Multilayer Perceptron Neural Network (MLP) [57-59], K-Nearest Neighbors [58] and Bayesian [60] based classifiers were tested. 


\section{Performance Evaluation Metrics}

In order to analyze the performance of the computer classifiers under comparison, a statistical metric was used: accuracy $(A c c)$, which is defined as the ratio between the number of feature classes correctly classified and the number of total feature classes of the problem:

$$
\text { Accuracy }=\frac{\# \text { Patterns correctly classified }}{\# \text { Patterns }}
$$

This metric was then used to evaluate the performance of the classifiers under comparison with high reliability.

\section{Results}

In this section, we present the results obtained by the computer classifiers under comparison when applied in the classification of induced magnetic field signals in order to identify sigma phase in a duplex stainless steel.

\subsection{Materials Characterization}

Figure 2 shows the variations of the induced magnetic field and of the impact energy in function of the content of sigma phase. The absorbed energy decreases rapidly and tends to a plateau as the material becomes brittle. Low content of the sigma phase promotes considerable decreasing of toughness; for example, $3 \%$ of content causes a reduction of $78 \%$ in the absorption of impact energy. The correlation between this phase and impact energy has been reported [7,61,62]. As already stated, sigma phase presents high hardness (around $900 \mathrm{HV}$ ) [12-14], which can compromise the material toughness [4,7,15]. According to Fargas et al. [61], as the precipitation of sigma phase increases, cracks occur preferentially in the contours of sigma phase particles oriented in the rolling direction. Thermal agings at 800 and $900{ }^{\circ} \mathrm{C}$ for $0.25 \mathrm{~h}$ lead to a loss in toughness of $31.3 \%$ and $54.5 \%$, respectively. In order to monitor duplex stainless steel structures, it is important to collect data below $0.5 \mathrm{~h}$, which corresponds to $2.84 \%$ of sigma phase. Normando et al. in [6], applied eddy current to follow sigma phase formation and showed that the impedance versus heat treatment at 800 and $900{ }^{\circ} \mathrm{C}$ decreases for times up to $2 \mathrm{~h}$. They noted a sharp decreasing of impedance in the first $15 \mathrm{~min}$, which they did not associate to sigma phase precipitation. Instead, the authors associated it to some second austenite phase precipitation, and also to a very sharp softening phase detected in the same interval. The authors only considered the effect of sigma phase over the impedance measurement for aging after $15 \mathrm{~min}$.

Figure 2 also provides evidence that the induced magnetic field follows the formation of sigma phase and that a critical value can be associated to the brittle condition of the studied material. Induced magnetic fields can be useful to monitor structures in service since they can allow the detection of small sigma phase content. This phase is paramagnetic and its formation reduced the permeability of the material and thus the induced magnetic field. Figure $2 \mathrm{~b}$ shows the reduction in the induced magnetic field due to the amount of sigma phase formed. From this figure, one can confirm that the proposed technique was able to follow the presence of this phase even in content below $4 \%$. Also from this figure, it can be noted that the content of sigma phase of $2.24 \%$ leads to a reduction of $31.3 \%$ in impact energy and of $2.84 \%$ to $78.5 \%$, respectively. Therefore, techniques to monitor the embrittlement of stainless steels need to be precise in this range of the sigma phase content. However, as previously mentioned, other non-destructive testing techniques, like eddy current and ultrasound, are not so effective in this range $[6,27]$. 


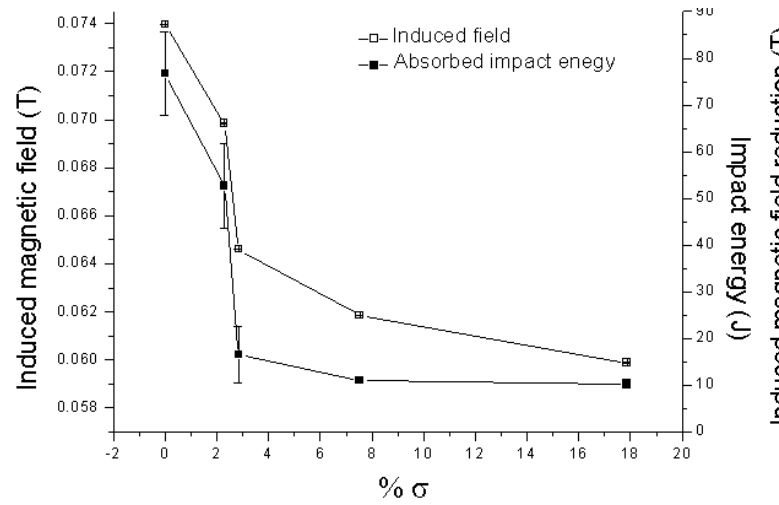

(a)

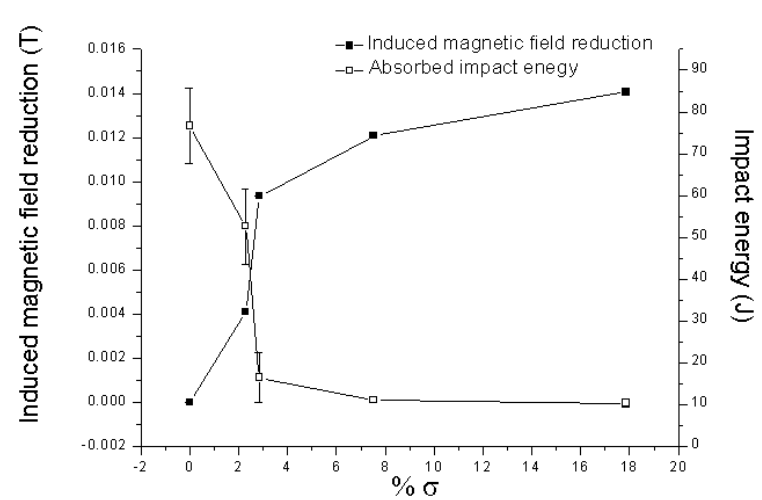

(b)

Figure 2. (a) Induced magnetic field and absorbed energy in terms of sigma phase percentage; (b) induced magnetic field reduction due to sigma phase in function of absorbed energy.

The precipitation of sigma phase, which is a paramagnetic phase, reduces the magnetic permeability of the steel as ferrite phase is ferromagnetic and decomposes into it. Magnetic susceptibility measurement has been used to study the decomposition of ferrite phase in duplex stainless steels at temperatures ranging between 350 and $900{ }^{\circ} \mathrm{C}[19,20]$. It was noticed that the magnetic susceptibility drops rapidly at the beginning and then levels off. For temperatures up to $550{ }^{\circ} \mathrm{C}$, ferrite decomposes via spinodal decomposition, and from 600 to $900{ }^{\circ} \mathrm{C}$, the magnetic susceptibility decreases because of the presence of sigma phase. The present magnetic technique was already applied to follow ferrite decomposition along aging temperatures above $550{ }^{\circ} \mathrm{C}$ and the results were similar [22].

Figure 3 shows the microstructures of the samples with different amounts of sigma phase (Figure 2) and their X-ray diffraction patterns. In the microstructures shown, sigma phase formed from ferrite sigma phase can be observed as well as the presence of sigma plus austenite phase reaction. It can be noted that, even with the random distribution of sigma phase in the material, the induced magnetic field allows the detection of this phase. In addition, a small percentage of chi phase also precipitated in duplex and super duplex steels from ferrite phase for aging temperatures between 700 and $900{ }^{\circ} \mathrm{C}[7,12]$. Figure 4 depicts the fracture surfaces analyzed from SEM of the samples with different amounts of sigma phase. In this figure, a change in the fracture mechanism from ductile to brittle can be observed. The sample with $2.24 \%$ of sigma phase revealed predominantly a ductile fracture mode, with a large number of deep dimples easily observed as well as the existence of some cracks. As the content of the phase reached a value of $2.84 \%$, transgranular and intergranular regions appeared. Delamination effects were also observed due to the easy crack propagation along the bands of ferrite and austenite. The content of $2.84 \%$ of sigma phase, which corresponds to the aging treatment at $800{ }^{\circ} \mathrm{C}$ for $0.25 \mathrm{~h}$, initiated a reduction of toughness around $78 \%$ in relation to the as-received material sample, which is in line with results that have been reported [15,61]. Above $2.84 \%$ of sigma phase, the material revealed to be brittle with increased number of delaminations. 


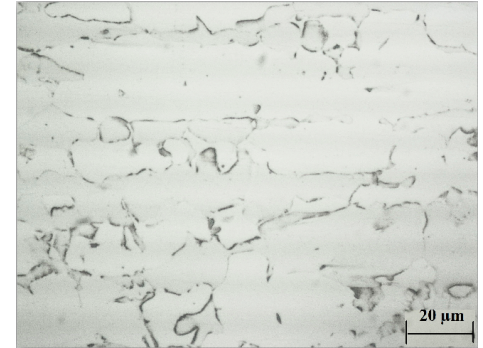

(a)

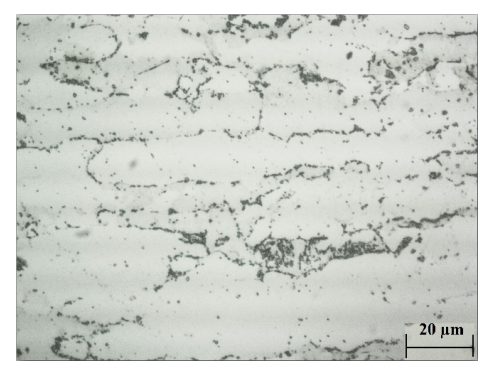

(c)

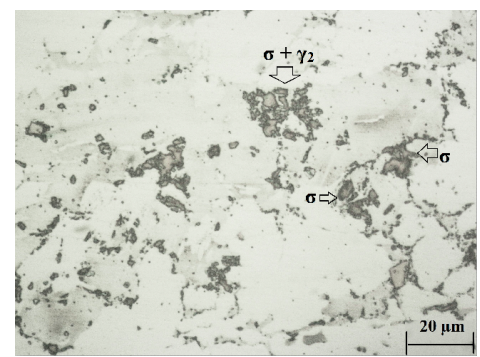

(e)

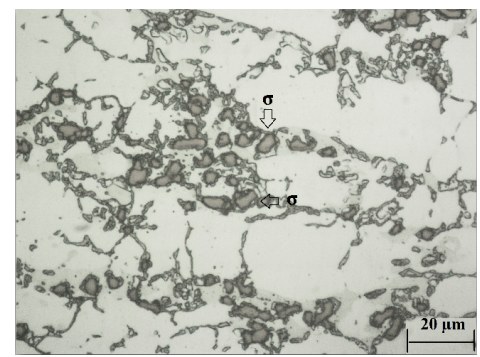

(g)

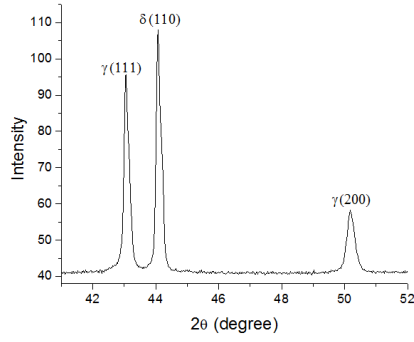

(b)

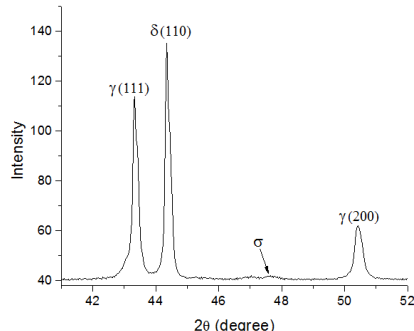

(d)

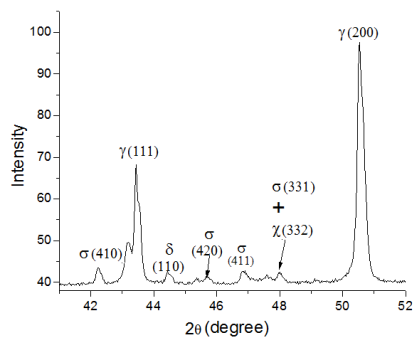

(f)

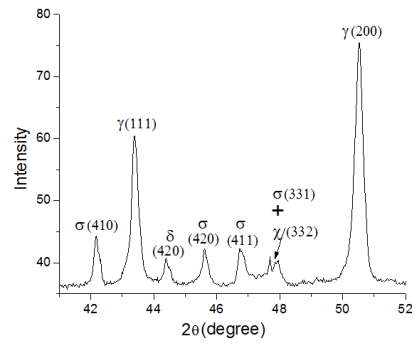

(h)

Figure 3. Microstructures of the studied samples with different contents of sigma phase and related X-ray diffractions, respectively: (a) 2.24\%; (b) 2.24\% (X-ray); (c) 2.84\%; (d) 2.84\% (X-ray); (e) 7.5\%; (f) $7.5 \%$ (X-ray); (g) 18\%; (h) 18\% (X-ray). ( $\sigma$ - sigma phase, $\gamma_{2}$ - austenite formed together with sigma phase.) 


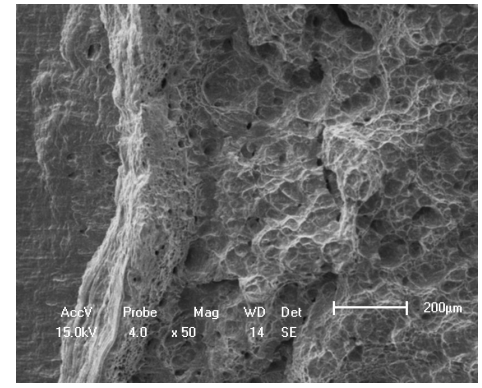

(a)

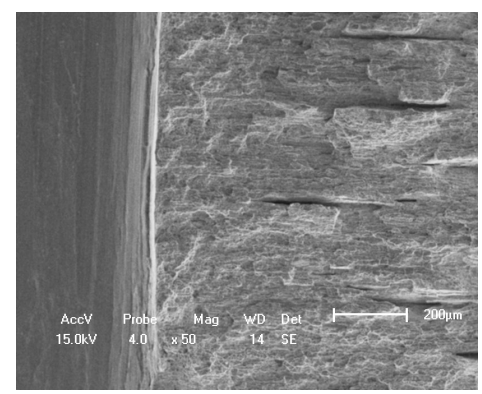

(c)

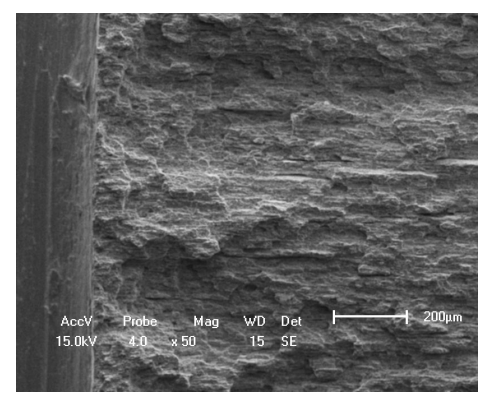

(e)

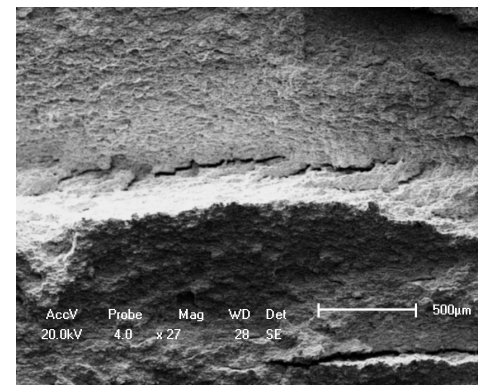

(g)

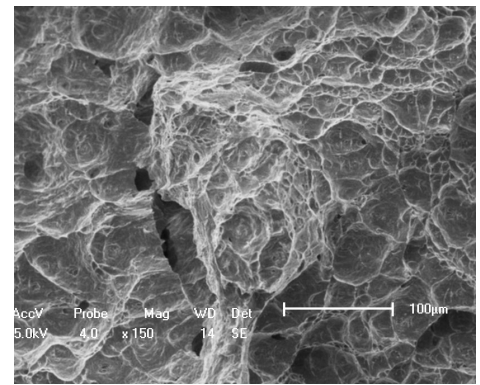

(b)

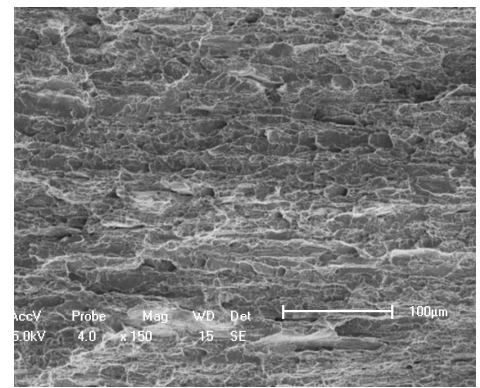

(d)

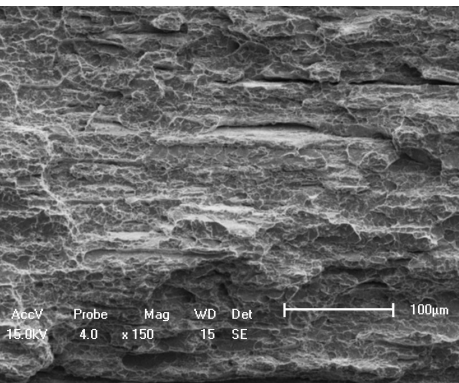

(f)

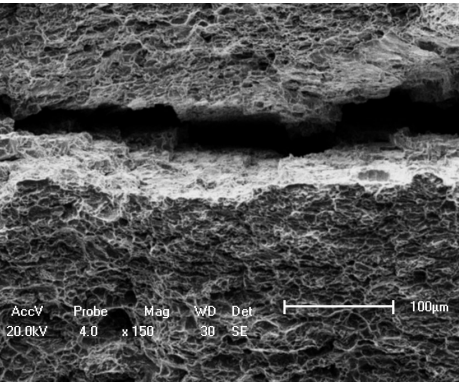

(h)

Figure 4. Fracture surface microstructures of the samples with different contents of sigma phase: (a) 2.24\%; predominantly ductile fracture; (b) $2.24 \%$, existence of some cracks; (c) $2.84 \%$, presence of cracks; (d) 2.84\%, transgranular and intergranular regions; (e) $7.5 \%$, brittle surface with delamination; (f) $7.5 \%$, detail of the delamination; (g) 18\%, brittle with increased delamination; and (h) $18 \%$, detail of the delamination.

\subsection{Computer Classification}

The classification experiments were carried out using computer classifiers in order to identify sigma phase in a duplex stainless steel from the raw data obtained from the magnetic induced field. The magnetic sensor used was built to provide low noisy data. However, the signal acquired can 
always be corrupted by noise. Therefore, the robustness of each classifier against noise was also investigated using Gaussian noise. Each signal to be classified had 500 attributes and three main components, which were determined by Principal Component Analysis (PCA), Figure 5.

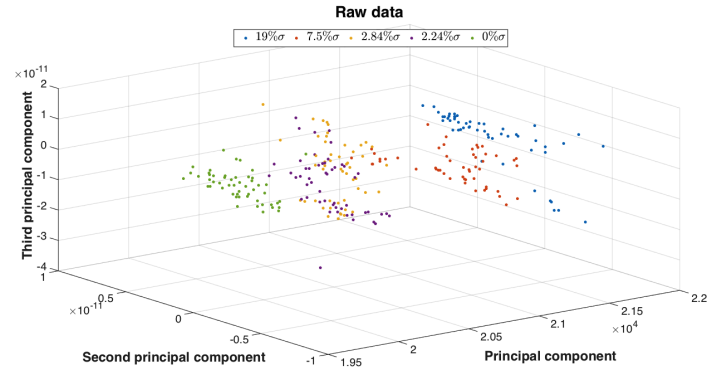

(a)

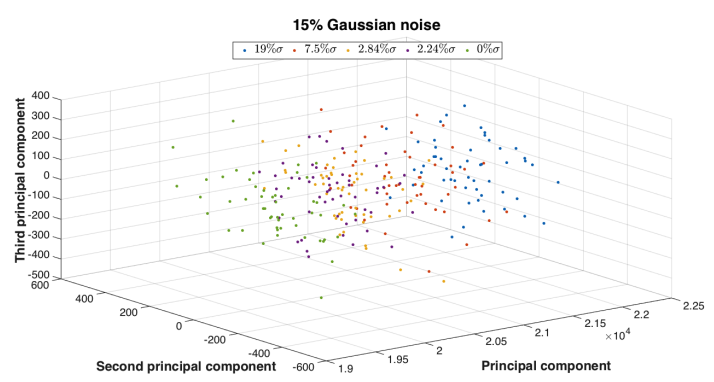

(c)

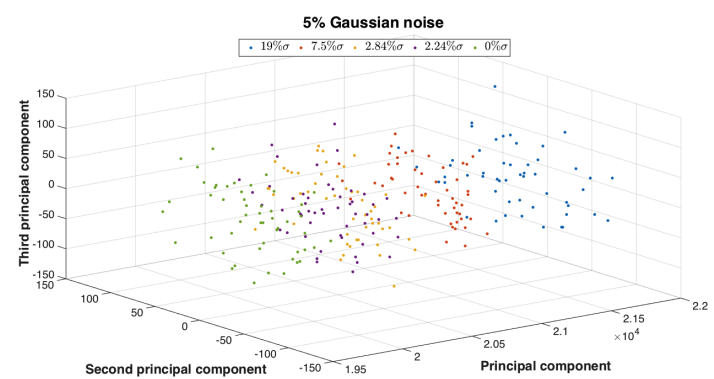

(b)

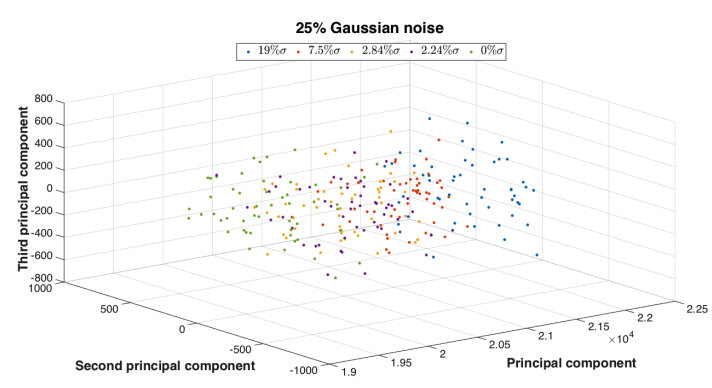

(d)

Figure 5. Distribution of the three main components of the induced magnetic field data for $0 \%, 2.24 \%$, $2.84 \%, 7.7 \%$ and $19 \%$ of sigma $(\sigma)$ phase: (a) raw data, and after the addition of (b) $5 \%$; (c) $15 \%$; and (d) $25 \%$ of Gaussian noise.

The computer classifiers under comparison are: kNN (k-Nearest Neighbour), Bayes, ANN (Artificial Neuronal Network), SVM with RBF kernel, and OPF with Canberra, Manhattan, Euclidean, square chi-square and Gaussian distances, which were tested using a notebook with an Intel Core i5 1.4 GHz processor, Santa Clara, CA, USA), 4 GB of RAM and running MAC OS X 10.10.5, Cupertino, CA, USA). Figures 6-8 show the results obtained based on the Holdolt method. According to this method, part of the samples are used to train and the remaining ones to test, i.e., to validate, the classifiers. Therefore, the training percentage used in the experiments varied from $10 \%$ to $90 \%$ with increments of $10 \%$, being the remaining samples used to test. Hence, for example, when $20 \%$ of the samples were used for training, $80 \%$ were used for testing.

Figure 6 a shows the accuracy obtained by each of the classifiers under comparison from the raw data signals, while Figure $6 \mathrm{~b}-\mathrm{d}$ shows the results obtained from the signals corrupted with the addition of $5 \%, 15 \%$, and $25 \%$ of Gaussian noise. It can be noted from Figure $6 \mathrm{a}$, that the OPF classifier obtained very good classification results (superior to $90 \%$ in terms of accuracy) independently of the percentage of the used training data and of the distance adopted. Also in terms of accuracy, SVM and Bayes based classifiers obtained results superior to $95 \%$ and $90 \%$, respectively. Additionally, it is worthwhile to note that OPF classifiers using Canberra, Gaussian and Euclidian distances had accuracies superior to $95 \%$.

From Figure $6 \mathrm{~b}-\mathrm{d}$, it can be observed that the classification accuracy decreased for of all classifiers with the addition of Gaussian noise. On average, the Bayes classifier lowered the accuracy rate from $94.12 \%$ obtained with the "uncorrupted" data, to $71.11 \%$ with the data $5 \%$ noise corrupted, and to $66.55 \%$ with the data $15 \%$ corrupted, and to $66.88 \%$ with the data $25 \%$ corrupted, respectively. On the other hand, SVM with RBF kernel classifier reduced on average the accuracy rate from $95 \%$ obtained with the original raw data, to $77.33 \%$ with the data corrupted with $5 \%$, to $74.88 \%$ with 
the data corrupted with $15 \%$, and to $70.44 \%$ with the data corrupted with $25 \%$ of Gaussian noise, respectively. As for the OPF classifier, it also reduced the classification accuracy from 95\% to 92\%, $76 \%$ and $73 \%$ with the data corrupted with $5 \%, 15 \%$, and $25 \%$ of Gaussian noise, respectively. It is noteworthy that OPF classifiers with Euclidian and Gaussian distances had excellent performances in all the tests, while the same classifiers with the remaining distances had alternating results.
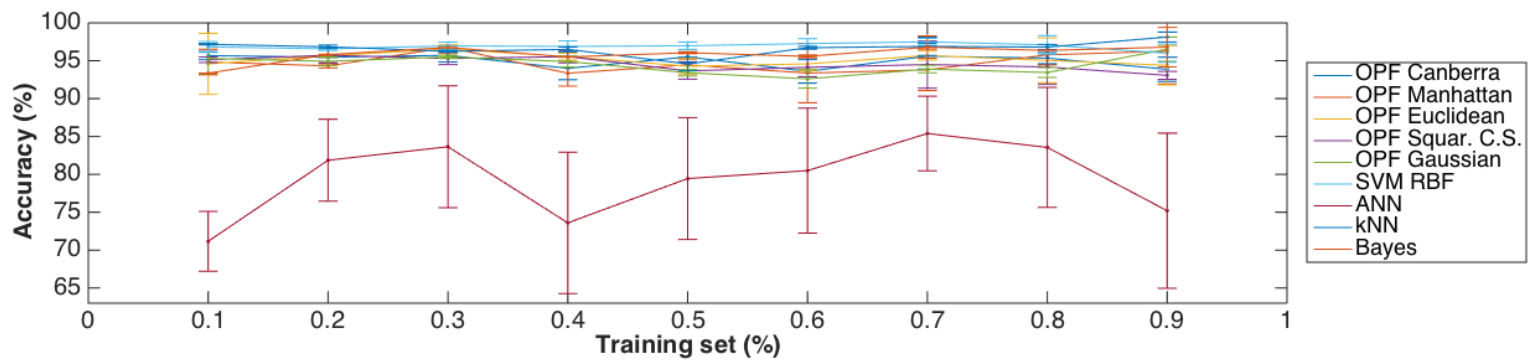

(a)
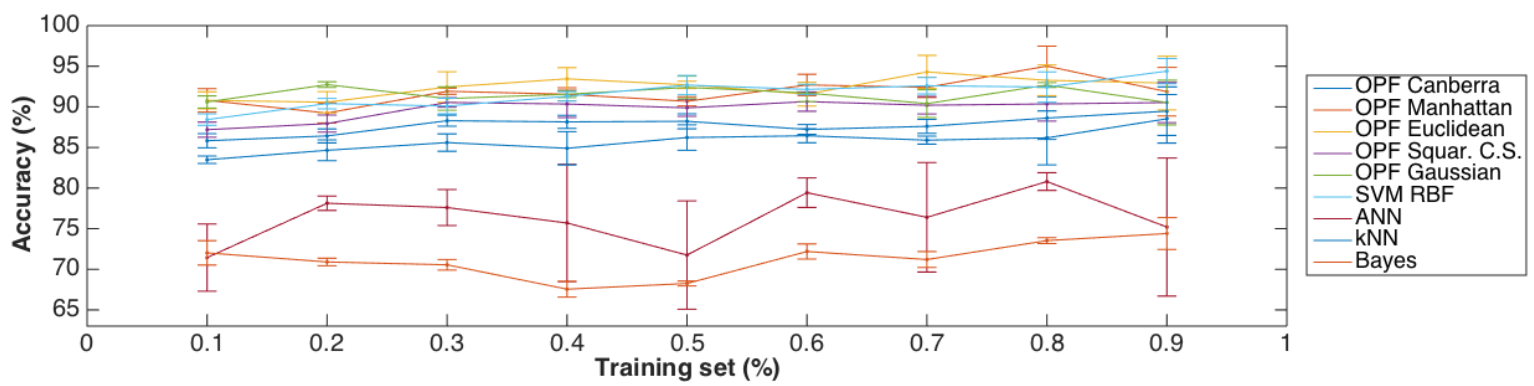

(b)
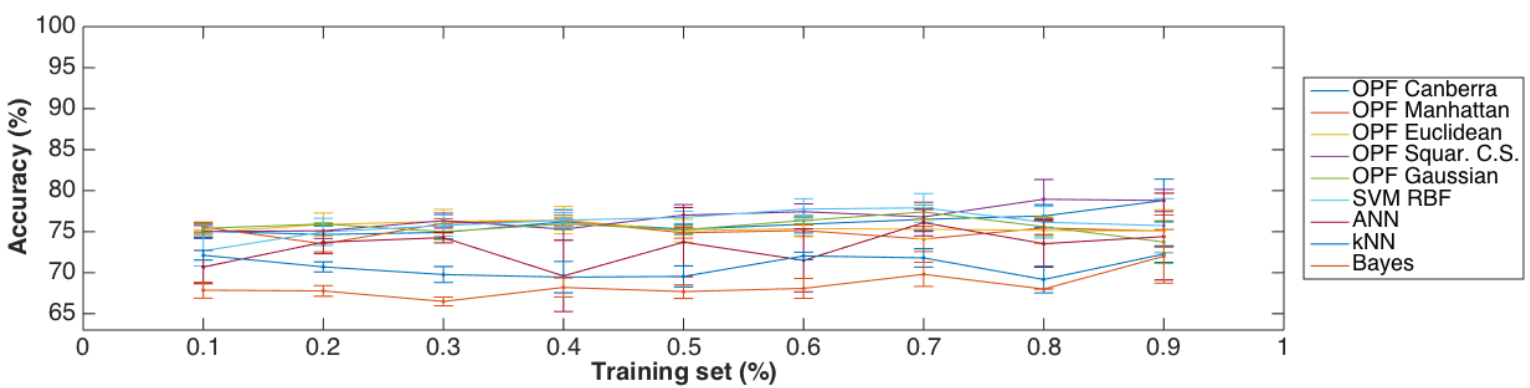

(c)
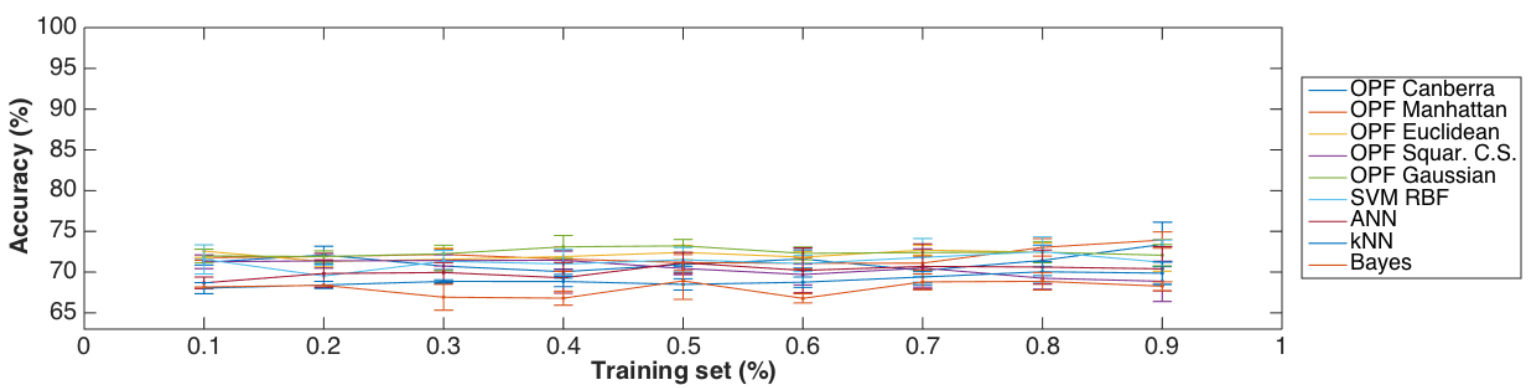

(d)

Figure 6. Accuracy obtained by the computer classifiers varying the used training data from $10 \%$ to $90 \%$ when applied on the original data and on the same data corrupted with the addition of Gaussian noise: (a) $0 \%$ (raw data); (b) 5\%; (c) $15 \%$; and (d) $25 \%$.

Figures 7 and 8 show the training and testing time required by the computer classifiers under comparison from the raw and signals corrupted with the addition of 5\%, 15\%, and 25\% of Gaussian 
noise. From these figures, it can be observed that OPF classifier using Canberra, Gaussian and Euclidian distances, had training times always less than $1 \mathrm{~ms}$ and test times inferior to $1 \mu \mathrm{s}$. The Bayes based classifier had training times about $2 \mathrm{~ms}$ and test times around $100 \mu \mathrm{s}$. It can also be verified that SVM classifier had increased training time with the increasing of the used training data percentage: for example, $92 \mathrm{~ms}$ with $10 \%$ and $5217 \mathrm{~ms}$ with $90 \%$, respectively. The classifier that had similar times to the OPF classifier was an ANN based classifier with test times of around $10 \mu \mathrm{s}$, but with higher training times (in the order of seconds) and lower accuracy rates. Taking into account the performance measure values, it can be realized that OPFs with Canberra distance had the best classification results.

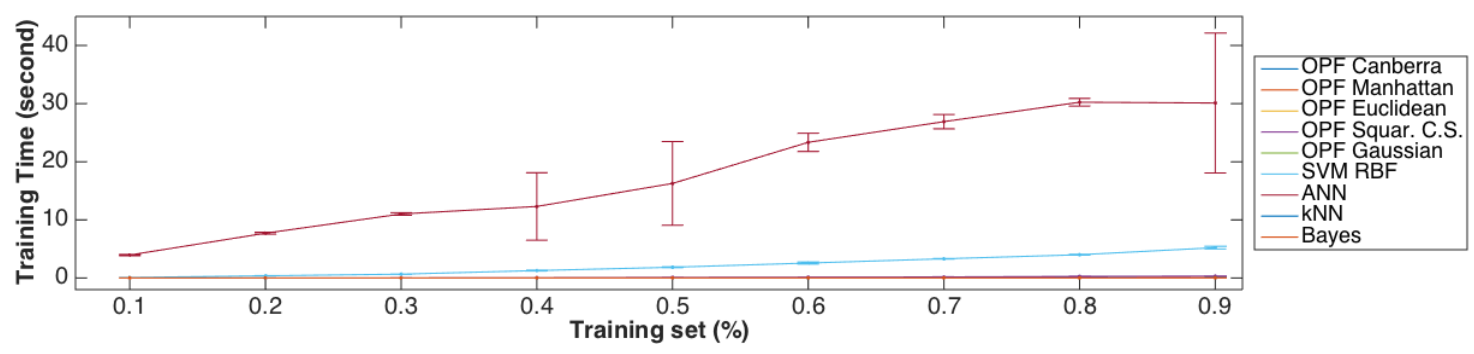

(a)

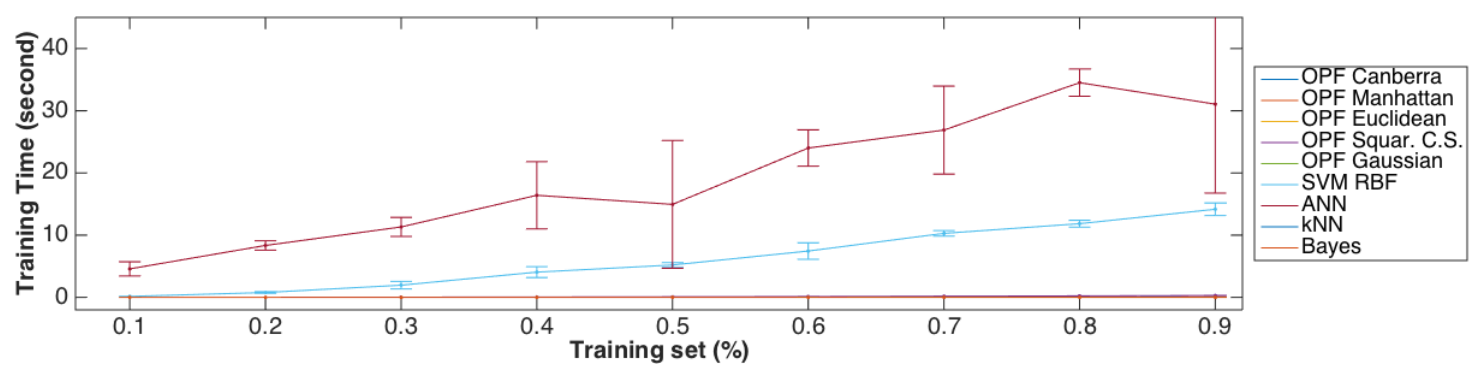

(b)

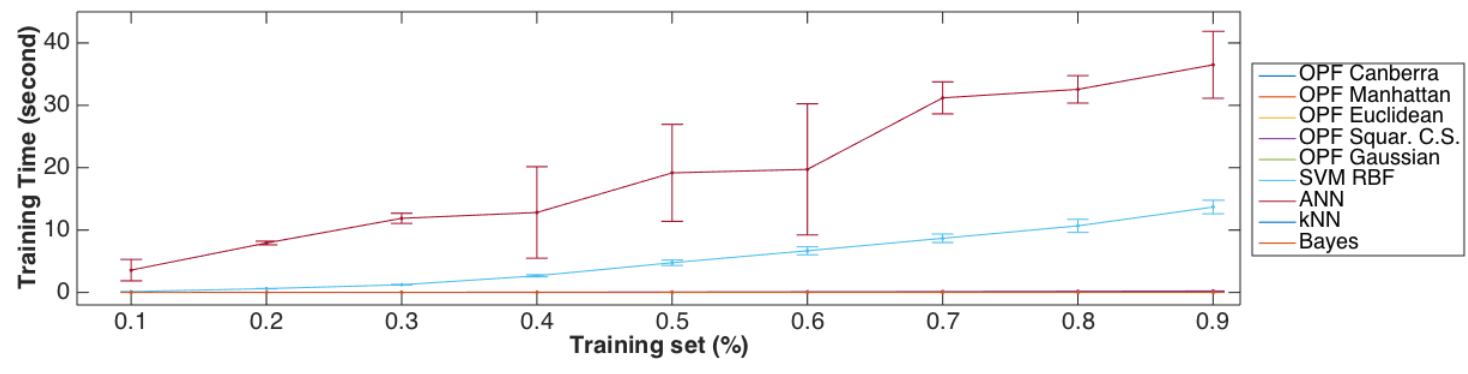

(c)

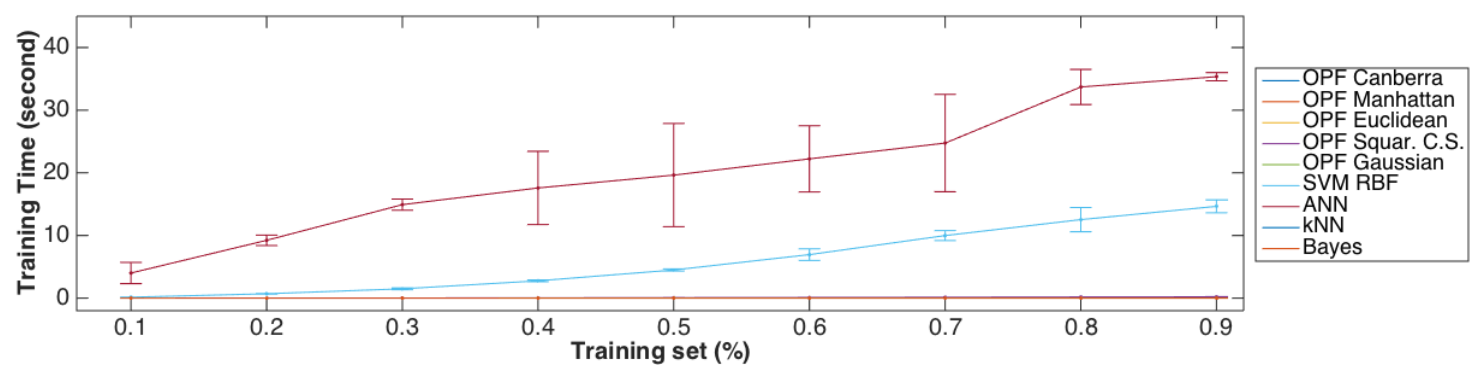

(d)

Figure 7. Training time required by the computer classifiers varying the percentage of the used training data from 10 to $90 \%$ when applied on the original data and on the same data corrupted with the addition of Gaussian noise: (a) 0\% (raw data); (b) 5\%; (c) 15\%; and (d) 25\%. 


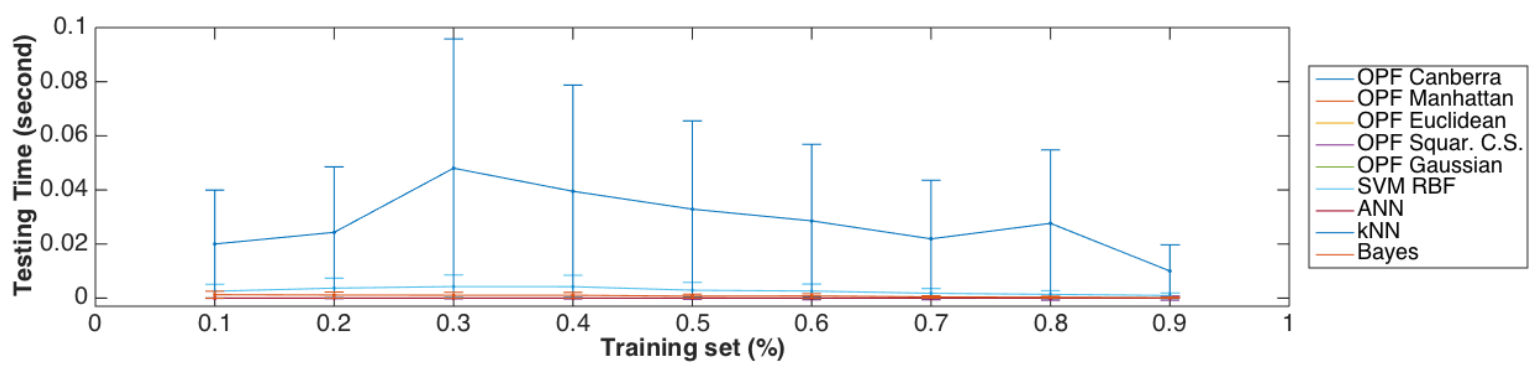

(a)

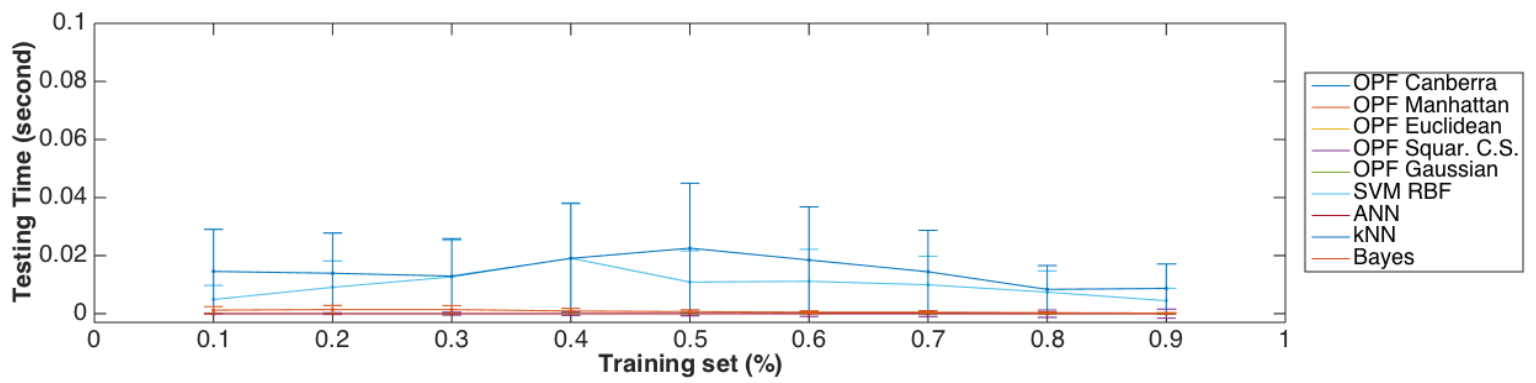

(b)

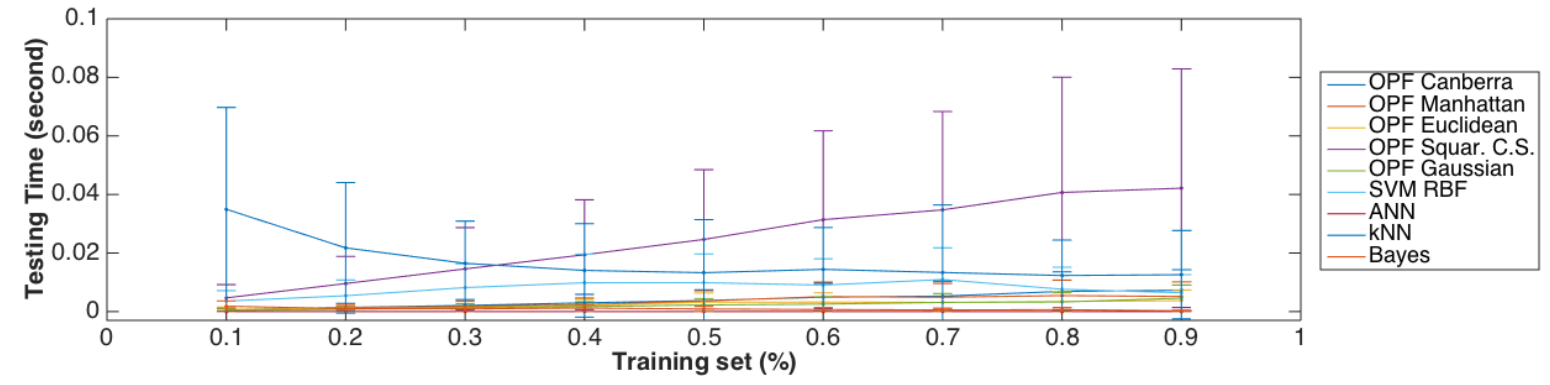

(c)

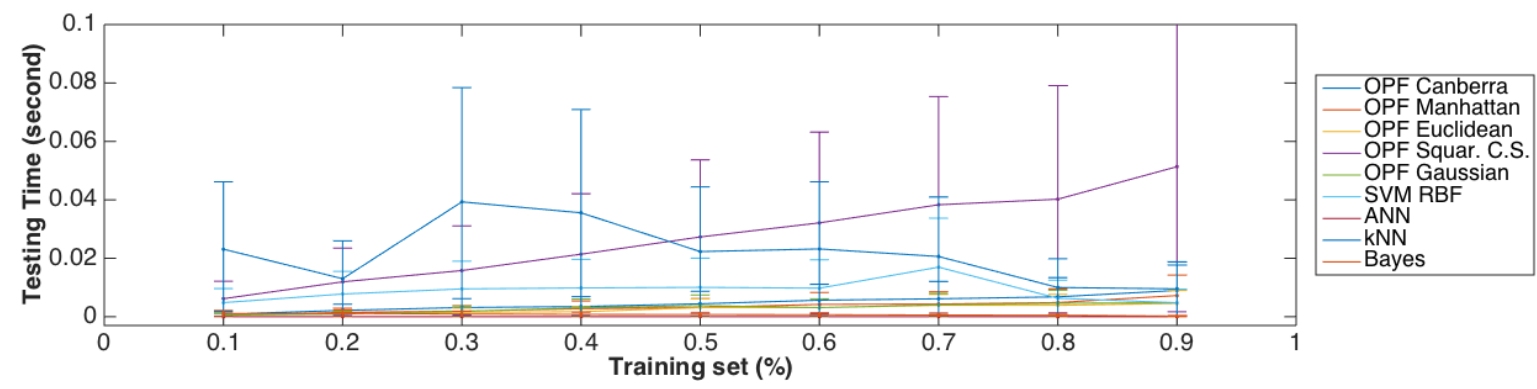

(d)

Figure 8. Testing time required by the computer classifiers varying the percentage of the used training data from 10 to $90 \%$ when applied on the original data and on the same data corrupted with the addition of Gaussian noise: (a) $0 \%$ (raw data); (b) $5 \%$; (c) $15 \%$; and (d) $25 \%$.

OPF classifier merits, like reduced training and testing times, observed in the classification results obtained from the original raw data, continued to be evident in the tests performed using the same data corrupted with Gaussian noise. In addition, it was clear that OPF classifiers were able to get very good accuracy rates, training and test times, independently of the used training data percentage. 


\section{Conclusions}

In this work, a solution for the automated detection of sigma phase in duplex stainless steels based on induced magnetic field signals and computer classification was proposed and evaluated.

Taking into account the conducted experiments, the following conclusions can be pointed out: OPF classifiers were more robust than the other studied classifiers since they obtained the best results, not only from the original raw data, but also from the noisy data. They also appeared to be more effective in terms of training, obtaining good classification results even when just $10 \%$ of the available data was used to train the classifiers, which did not happen with the other classifiers. Another observed advantage is that the training and test times of OPF classifiers did not vary notably with the used training data percentage, since they had similar training speeds when $10 \%$ and $90 \%$ of the training data were used.

Therefore, the proposed solution for the automatic identification of sigma phase in duplex steels is very promising, as it achieved accuracy rates superior to $95 \%$, and proved to be able to achieve good performance even when the signal data is corrupted with noise.

Acknowledgments: Edgard de Macedo Silva acknowledges the sponsorship from the Coordination for the Improvement of Higher Education Personnel (CAPES), in Brazil, through the scholarship process BEX 2634/15-5 at Faculdade de Engenharia da Universidade do Porto (FEUP), in Portugal, and from the Federal Institution of Paraiba (IFPB) in Brazil. Pedro P. Rebouças Filho acknowledges the sponsorship from the Brazilian National Council for Research and Development (CNPq) through Grants 232644/2014-4. Victor Hugo C. de Albuquerque acknowledges CNPq through Grants 470501/2013-8 and 301928/2014-2. João Manuel R.S. Tavares gratefully acknowledges the funding of Project NORTE-01-0145-FEDER-000022—SciTech - Science and Technology for Competitive and Sustainable Industries, cofinanced by "Programa Operacional Regional do Norte" (NORTE2020), through “Fundo Europeu de Desenvolvimento Regional” (FEDER).

Author Contributions: Study design: E. Silva, J. Tavares, P. Rebouças Filho and V. Albuquerque; Experimental work: L. Marinho, João Leite, Josinaldo Leite and W. Fialho; Results analysis and manuscript preparation: all authors; Manuscript proof and Submission: J. Tavares.

Conflicts of Interest: The authors declare no conflict of interest.

\section{References}

1. Martins, M.; Casteletti, L.C. Microstructural characteristics and corrosion behavior of a super duplex stainless steel casting. Mater. Charact. 2009, 60, 150-155.

2. Badji, R.; Bouabdallah, M.; Bacroix, B.; Kahloun, C.; Bettahar, K.; Kherrouba, N. Effect of solution treatment temperature on the precipitation kinetic of $\sigma$-phase in 2205 duplex stainless steel welds. Mater. Sci. Eng. A 2008, 496, 447-454.

3. Jiang, Z.; Chen, X.; Huang, H.; Liu, X. Grain refinement of Cr25Ni5Mo1.5 duplex stainless steel by heat treatment. Mater. Sci. Eng. A 2003, 363, 263-267.

4. Chen, T.; Weng, K.; Yang, J. The effect of high-temperature exposure on the microstructural stability and toughness property in a 2205 duplex stainless steel. Mater. Sci. Eng. A 2002, 338, 259-270.

5. Pohl, M.; Storz, O.; Glogowski, T. Effect of intermetallic precipitations on the properties of duplex stainless steel. Mater. Charact. 2007, 58, 65-71.

6. Normando, P.G.; Moura, E.P.; Souza, J.A.; Tavares, S.S.; Padovese, L.R. Ultrasound, eddy current and magnetic Barkhausen noise as tools for sigma phase detection on a UNS S31803 duplex stainless steel. Mater. Sci. Eng. A 2010, 527, 2886-2891.

7. Tavares, S.; Pardal, J.; Guerreiro, J.; Gomes, A.; da Silva, M. Magnetic detection of sigma phase in duplex stainless steel UNS S31803. J. Magn. Magn. Mater. 2010, 322, L29-L33.

8. Sieurin, H.; Sandström, R. Sigma phase precipitation in duplex stainless steel 2205. Mater. Sci. Eng. A 2007, 444, 271-276.

9. Muthupandi, V.; Srinivasan, P.B.; Seshadri, S.; Sundaresan, S. Effect of weld metal chemistry and heat input on the structure and properties of duplex stainless steel welds. Mater. Sci. Eng. A 2003, 358, 9-16. 
10. Pardal, J.M.; Tavares, S.S.M.; Fonseca, M.P.C.; da Silva, M.R.; Ferreira, M.L.R. Study of deleterious phase precipitation under continuous cooling of superduplex stainless steel UNS S32750. Mater. Sci. Technol. 2012, 28, 295-302.

11. Junior, C.M.S.; Abreu, H.F.G.; Tavares, S.S.M.; Rebello, J.M.A. The $\sigma$ phase formation in annealed UNS S31803 duplex stainless steel: Texture aspects. Mater. Charact. 2008, 59, 1301-1306.

12. Sathirachinda, N.; Pettersson, R.; Pan, J. Depletion effects at phase boundaries in 2205 duplex stainless steel characterized with \{SKPFM $\}$ and TEM/EDS. Corros. Sci. 2009, 51, 1850-1860.

13. Moura, V.S.; Lima, L.D.; Pardal, J.M.; Kina, A.Y.; Corte, R.R.A.; Tavares, S.S.M. Influence of microstructure on the corrosion resistance of the duplex stainless steel UNS S31803. Mater. Charact. 2008, 59, 1127-1132.

14. Zou, D.; Han, Y.; Zhang, W.; Fan, G. Phase Transformation and Its Effects on Mechanical Properties and Pitting Corrosion Resistance of 2205 Duplex Stainless Steel. J. Iron Steel Res. Int. 2010, 17, 67-72.

15. Zhang, W.; Jiang, L.; Hu, J.; Song, H. Effect of ageing on precipitation and impact energy of 2101 economical duplex stainless steel. Mater. Charact. 2009, 60, 50-55.

16. Nilsson, J.O.; Kangas, P.; Wilson, A.; Karlsson, T. Mechanical properties, microstructural stability and kinetics of $\sigma$-phase formation in $29 \mathrm{Cr}-6 \mathrm{Ni}-2 \mathrm{Mo}-0.38 \mathrm{~N}$ superduplex stainless steel. Metall. Mater. Trans. A 2000, 31, 35-45.

17. Mohapatra, J.N.; Kamada, Y.; Kikuchi, H.; S. Kobayashi, J.E.; Park, D.G.; Cheong, Y.M. Evaluation of Embrittlement in Isochronal Aged Fe-Cr Alloys by Magnetic Hysteresis Loop Technique. Metall. Mater. Trans. A 2011, 16, 173-176.

18. Mohapatra, J.; Kamada, Y.; Murakami, T.; Echigoya, J.; Kikuchi, H.; Kobayashi, S. Magnetic hysteresis loop technique as a tool for the evaluation of $\sigma$ phase embrittlement in Fe-Cr alloys. J. Magn. Magn. Mater. 2013, 327, 71-75.

19. Lo, K.; Lai, J.; Shek, C.; Li, D. Magnetic and transformation behaviour of duplex stainless steels under non-isothermal conditions and temperature-fluctuation monitoring. Mater. Sci. Eng. A 2007, 452-453, 149-160.

20. Lo, K.; Lai, J. Microstructural characterisation and change in a.c. magnetic susceptibility of duplex stainless steel during spinodal decomposition. J. Nucl. Mater. 2010, 401, 143-148.

21. Ghanei, S.; Kashefi, M.; Mazinani, M. Eddy current nondestructive evaluation of dual phase steel. Mater. Des. 2013, 50, 491-496.

22. De Macedo Silva, E.; Leite, J.P.; de França Neto, F.A.; Leite, J.P.; Fialho, W.M.; de Albuquerque, V.C.; Tavares, J.R. Evaluation of the Magnetic Permeability for the Microstructural Characterization of a Duplex Stainless Steel. J. Test. Eval. 2016, 44, doi:10.1520/JTE20130313.

23. Camerini, C.; Sacramento, R.; Areiza, M.; Rocha, A.; Santos, R.; Rebello, J.; Pereira, G. Eddy current techniques for super duplex stainless steel characterization. J. Magn. Magn. Mater. 2015, 388, 96-100.

24. Rebello, J.; Areiza, M.; Camerini, C.; Rocha, J. Saturated low frequency eddy current technique applied to microstructure phase quantification in duplex stainless steel. In Proceedings of the 2013 Far East Forum on Nondestructive Evaluation/Testing: New Technology Application (FENDT), Jinan, China, 17-20 June 2013; pp. 1-7.

25. Uchimoto, T.; Takagi, T.; Konoplyuk, S.; Abe, T.; Huang, H.; Kurosawa, M. Eddy current evaluation of cast irons for material characterization. J. Magn. Magn. Mater. 2003, 258-259, 493-496.

26. Rebello, J.M.A.; Sacramento, R.; Areiza, M.C.L.; de Assis, K.S. Quantification of Sigma Phase Precipitation by Magnetic Non Destructive Testing. In Electromagnetic Nondestructive Evaluation-Studies in Applied Electromagnetics and Mechanics; IOS Press: Amsterdam, The Netherlands, 2010; Volume 35, pp. 311-321.

27. Nunes, T.M.; de Albuquerque, V.H.C.; Papa, J.P.; Silva, C.C.; Normando, P.G.; Moura, E.P.; Tavares, J.M.R. Automatic microstructural characterization and classification using artificial intelligence techniques on ultrasound signals. Expert Syst. Appl. 2013, 40, 3096-3105.

28. De Albuquerque, V.H.C.; de Macedo Silva, E.; Leite, J.P.; de Moura, E.P.; de Araújo Freitas, V.L.; Tavares, J.M.R. Spinodal decomposition mechanism study on the duplex stainless steel UNS S31803 using ultrasonic speed measurements. Mater. Des. 2010, 31, 2147-2150.

29. De Albuquerque, V.H.C.; Silva, C.C.; Normando, P.G.; Moura, E.P.; Tavares, J.M.R. Thermal aging effects on the microstructure of $\mathrm{Nb}$-bearing nickel based superalloy weld overlays using ultrasound techniques. Mater. Des. 2012, 36, 337-347. 
30. De Macedo Silva, E.; de Albuquerque, V.H.C.; Leite, J.P.; Varela, A.C.G.; de Moura, E.P.; Tavares, J.M.R. Phase transformations evaluation on a UNS S31803 duplex stainless steel based on nondestructive testing. Mater. Sci. Eng. A 2009, 516, 126-130.

31. De Albuquerque, V.H.C.; de A. Melo, T.A.; de Oliveira, D.F.; Gomes, R.M.; Tavares, J.M.R. Evaluation of grain refiners influence on the mechanical properties in a CuAlBe shape memory alloy by ultrasonic and mechanical tensile testing. Mater. Des. 2010, 31, 3275-3281.

32. De Araújo Freitas, V.L.; de Albuquerque, V.H.C.; de Macedo Silva, E.; Silva, A.A.; Tavares, J.M.R. Nondestructive characterization of microstructures and determination of elastic properties in plain carbon steel using ultrasonic measurements. Mater. Sci. Eng. A 2010, 527, 4431-4437.

33. Tavares, J.M.R.; Rebouças Filho, P.P.; Cavalcante, T.D.S.; de Albuquerque, V.H.C. Brinell and Vickers hardness measurement using image processing and analysis techniques. J. Test. Eval. 2009, 38, 1-7.

34. De Macêdo Peixoto, F.; de Souza Rebouças, E.; de Lima Xavier, F.G.; Rebouças Filho, P.P. Software development for ductile cast iron graphite nodules density calculation using Digital Image Processing. Matéria (Rio de Janeiro) 2015, 20, 262-272.

35. Rebouças Filho, P.P.; Moreira, F.D.L.; Xavier, F.G.d.L.; Gomes, S.L.; Santos, J.C.d.; Freitas, F.N.C.; Freitas, R.G. New Analysis Method Application in Metallographic Images through the Construction of Mosaics Via Speeded Up Robust Features and Scale Invariant Feature Transform. Materials 2015, 8, 3864-3882.

36. De Albuquerque, V.H.C.; Barbosa, C.V.; Silva, C.C.; Moura, E.P.; Filho, P.P.R.; Papa, J.P.; Tavares, J.M.R.S. Ultrasonic Sensor Signals and Optimum Path Forest Classifier for the Microstructural Characterization of Thermally-Aged Inconel 625 Alloy. Sensors 2015, 15, 12474.

37. Moreira, F.D.L.; Kleinberg, M.N.; Arruda, H.F.; Freitas, F.N.C.; Parente, M.M.V.; de Albuquerque, V.H.C.; Rebouças Filho, P.P. A novel Vickers hardness measurement technique based on Adaptive Balloon Active Contour Method. Expert Syst. Appl. 2016, 45, 294-306.

38. De Albuquerque, V.H.C.; de Alexandria, A.R.; Cortez, P.C.; Tavares, J.M.R. Evaluation of multilayer perceptron and self-organizing map neural network topologies applied on microstructure segmentation from metallographic images. NDT E Int. 2009, 42, 644-651.

39. Albuquerque, V.H.C.; Rebouças Filho, P.P.; Cavalcante, T.S.; Tavares, J.M.R.S. New computational solution to quantify synthetic material porosity from optical microscopic images. J. Microsc. 2010, 240, 50-59.

40. Albuquerque, V.H.C.D.; Tavares, J.M.R.; Cortez, P.C. Quantification of the microstructures of hypoeutectic white cast iron using mathematical morphology and an artificial neural network. Int. J. Microstruct. Mater. Prop. 2010, 5, 52-64.

41. Albuquerque, V.H.C.; Tavares, J.M.R.S.; Durão, L.M.D. Evaluation of Delamination Damage on Composite Plates using an Artificial Neural Network for the Radiographic Image Analysis. J. Compos. Mater. 2010, 44, 1139-1159.

42. De Albuquerque, V.H.C.; Silva, C.C.; Menezes, T.I.d.S.; Farias, J.P.; Tavares, J.M.R.S. Automatic evaluation of nickel alloy secondary phases from SEM images. Microsc. Res. Tech. 2011, 74, 36-46.

43. De Albuquerque, V.H.C.; Cortez, P.C.; de Alexandria, A.R.; Tavares, J.M.R. A new solution for automatic microstructures analysis from images based on a backpropagation artificial neural network. Nondestruct. Test. Eval. 2008, 23, 273-283.

44. Papa, J.P.; Falcao, A.X.; Suzuki, C.T.N. Supervised Pattern Classification based on Optimum-Path Forest. Int. J. Imaging Syst. Technol. 2009, 19, 120-131.

45. Papa, J.P.; Falcao, A.X.; de Albuquerque, V.H.C.; Tavares, J.M.R.S. Efficient supervised optimum-path forest classification for large datasets. Pattern Recognit. 2012, 45, 512-520.

46. Iwashita, A.; Papa, J.; Souza, A.; Falcao, A.; Lotufo, R.; Oliveira, V.; de Albuquerque, V.H.C.; Tavares, J.M.R. A path- and label-cost propagation approach to speedup the training of the optimum-path forest classifier. Pattern Recogniti. Lett. 2014, 40, 121-127.

47. Osaku, D.; Nakamura, R.; Pereira, L.; Pisani, R.; Levada, A.; Cappabianco, F.; Falcao, A.; Papa, J.P. Improving land cover classification through contextual-based optimum-path forest. Inf. Sci. 2015, 324, 60-87.

48. Luz, E.J.S.; Nunes, T.M.; de Albuquerque, V.H.C.; Papa, J.P.; Menotti, D. ECG arrhythmia classification based on optimum-path forest. Expert Syst. Appl. 2013, 40, 3561-3573. 
49. Nunes, T.M.; Coelho, A.L.; Lima, C.A.; Papa, J.P.; de Albuquerque, V.H.C. EEG signal classification for epilepsy diagnosis via optimum path forest - A systematic assessment. Neurocomputing 2014, 136, 103-123.

50. Papa, J.P.; Nakamura, R.Y.; de Albuquerque, V.H.C.; Falcao, A.X.; Tavares, J.M.R. Computer techniques towards the automatic characterization of graphite particles in metallographic images of industrial materials. Expert Syst. Appl. 2013, 40, 590-597.

51. Pisani, R.; Nakamura, R.M.; Riedel, P.S.; Zimback, C.L.; Falcao, A.X.; Papa, J. Toward Satellite-Based Land Cover Classification Through Optimum-Path Forest. IEEE Trans. Geosci. Remote Sens. 2014, 52, 6075-6085.

52. Saito, P.T.M.; Nakamura, Y.M.R.; Amorim, W.P.; Papa, J.P.; Rezende, P.J.; Falcao, A.X. Choosing the Most Effective Pattern Classification Model under Learning-Time Constraint. PLoS ONE 2015, 10, e0129947.

53. Suzuki, C.; Gomes, J.; Falcao, A.; Papa, J.; Hoshino-Shimizu, S. Automatic Segmentation and Classification of Human Intestinal Parasites From Microscopy Images. IEEE Trans. Biomed. Eng. 2013, 60, 803-812.

54. Pereira, C.R.; Nakamura, R.Y.; Costa, K.A.; Papa, J.P. An Optimum-Path Forest framework for intrusion detection in computer networks. Eng. Appl. Artif. Intell. 2012, 25, 1226-1234.

55. Burges, C.J.C. A tutorial on support vector machines for pattern recognition. Data Min. Knowl. Discov. 1998, 2, 121-167.

56. Chang, C.C.; Lin, C.J. LIBSVM: A Library for Support Vector Machines. ACM Trans. Intell. Syst. Technol. 2011, 2, doi:10.1145/1961189.1961199.

57. Rebouças Filho, P.P.; Cortez, P.C.; da Silva Barros, A.C.; de Albuquerque, V.H.C. Novel Adaptive Balloon Active Contour Method based on internal force for image segmentation-A systematic evaluation on synthetic and real images. Expert Syst. Appl. 2014, 41, 7707-7721.

58. Neto, E.C.; Gomes, S.L.; Rebouças Filho, P.P.; de Albuquerque, V.H.C. Brazilian vehicle identification using a new embedded plate recognition system. Measurement 2015, 70, 36-46.

59. Neto, E.C.; Reboucas, E.S.; de Moraes, J.L.; Gomes, S.L.; Filho, P.P.R. Development control parking access using techniques Digital Image Processing and Applied Computational Intelligence. IEEE Latin Am. Trans. 2015, 13, 272-276.

60. Duda, R.O.; Hart, P.E.; Stork, D.G. Pattern Classification, 2nd ed.; Wiley-Interscience: New York City, NY, USA, 2000.

61. Fargas, G.; Anglada, M.; Mateo, A. Effect of the annealing temperature on the mechanical properties, formability and corrosion resistance of hot-rolled duplex stainless steel. J. Mater. Process. Technol. 2009, 209, 1770-1782.

62. Martins, M.; Forti, L.R.N. Effect of aging on impact properties of ASTM A890 Grade 1C super duplex stainless steel. Mater. Charact. 2008, 59, 162-166.

(c) 2016 by the authors; licensee MDPI, Basel, Switzerland. This article is an open access article distributed under the terms and conditions of the Creative Commons Attribution (CC-BY) license (http://creativecommons.org/licenses/by/4.0/). 